\title{
Article \\ Research on the Fracture Behavior of Steel-Fiber-Reinforced High-Strength Concrete
}

\author{
Shanming Qin ${ }^{1}$, Danying Gao ${ }^{1}$, Zhanqiao Wang ${ }^{1, *}$ and Haitang Zhu ${ }^{1,2}$ \\ 1 School of Water Conservancy Engineering, Zhengzhou University, Zhengzhou 450001, China; \\ qinshanming0210@163.com (S.Q.); gdy@zzu.edu.cn (D.G.); htzhu@zzu.edu.cn (H.Z.) \\ 2 College of Civil Engineering, Henan University of Engineering, Zhengzhou 451191, China \\ * Correspondence: wzqzzu@zzu.edu.cn; Tel.: +86-136-7336-7791
}

check for updates

Citation: Qin, S.; Gao, D.; Wang, Z.; Zhu, H. Research on the Fracture Behavior of Steel-Fiber-Reinforced High-Strength Concrete. Materials 2022, 15, 135. https://doi.org/ $10.3390 / \mathrm{ma} 15010135$

Academic Editors: Alessandro P. Fantilli and Dario De Domenico

Received: 12 October 2021

Accepted: 21 December 2021

Published: 24 December 2021

Publisher's Note: MDPI stays neutral with regard to jurisdictional claims in published maps and institutional affiliations.

Copyright: (C) 2021 by the authors. Licensee MDPI, Basel, Switzerland. This article is an open access article distributed under the terms and conditions of the Creative Commons Attribution (CC BY) license (https:// creativecommons.org/licenses/by/ $4.0 /)$.

\begin{abstract}
The behavior of steel fiber concrete, which is the most widely used building material, has been widely examined. However, methods for calculating Fracture parameters differ by fracture behavior of SFHSC with different strengths. In this study, the fracture behavior of steel-fiberreinforced high-strength concrete (SFHSC) was -investigated using three-point bending tests. A total of 144 notched concrete beams with a size of $100 \mathrm{~mm} \times 100 \mathrm{~mm} \times 515 \mathrm{~mm}$ were tested for three-point bending in 26 groups. The effects of the steel fiber volume ratio, steel fiber type, and relative notch depth on the fracture toughness $\left(\mathrm{K}_{\mathrm{IC}}\right)$ and fracture energy $\left(\mathrm{G}_{\mathrm{F}}\right)$ of SFHSC specimens were studied. The results show that an increase in the volume fraction of steel fiber $\left(\rho_{f}\right)$ added to high-strength concrete (HSC) significantly improves the fracture behavior of HSC. As compared to milled and sheared corrugated steel fibers, cut bow steel fibers significantly improve the fracture behavior of SFHSC. The effect of incision depth changes on the $\mathrm{K}_{\mathrm{IC}}$ and $\mathrm{G}_{\mathrm{F}}$ of SFHSC and HSC for the comparison group has no common characteristics. With an increase in incision depth, the values of $\mathrm{K}_{\mathrm{IC}}$ of the SFHSC specimens decrease slightly. The $\mathrm{G}_{\mathrm{F} 0.5} / \mathrm{G}_{\mathrm{F} 0.4}$ of the SFHSC specimens show a decreasing trend with an increase in $\rho_{f}$. According to the test results, we propose calculation models for the fracture behavior of SFHSC with different strengths. Thus, we present a convenient and accurate method to calculate fracture parameters, which lays a foundation for subsequent research.
\end{abstract}

Keywords: steel fiber reinforced high-strength concrete; fracture toughness; fracture energy; threepoint bending test

\section{Introduction}

With the development of modern building technology, numerous varied complex structures have emerged with cement concrete performance requirements; therefore, methods for improving the performance of concrete are always of interest to researchers [1,2]. Currently, there is an increasing demand for high-strength or even ultrahigh-strength concrete, with low cost and few construction difficulties [3]. High-strength concrete (HSC) is a typical representative of concrete in the high-tech era; however, it is more brittle than ordinary concrete, and damage often occurs suddenly and without warning. Undoubtedly, many unsafe factors are added to large and complex concrete structures $[4,5]$.

To enhance the strength of the concrete matrix and to reduce the toughness, investigators have trialed different treatments. Studies have found that merging fibers into concrete can enhance the tensile strength, fracture toughness, dynamic mechanical properties, and the durability of concrete [6-8]. Fiber types such as carbon fiber, polypropylene, glass, and steel fiber are commonly used to enhance the strength of the concrete matrix [9-11]. Among the various suggested approaches, the implementation of steel fibers is one of the most widely exploited methods to improve the concrete mechanical behavior because it is easily available and contained within the concrete mix [12]. The most advantageous element of steel fiber is that it increases the ductility of concrete after microcracks are formed [13-18]. The addition of steel fiber to concrete changes the strain capacity and reduces the brittleness 
of HSC [19]. A study by Yoo et al. [20] showed that steel fiber contents of over 1.0\% could significantly improve the post-peak ductility and compressive strength of concrete. Şemsi et al. [21] reached a similar conclusion. Therefore, in order to improve the mechanical properties of HSC and increase the cracking strength, a specific amount of steel fiber is usually added to the HSC matrix. SFHSC has excellent mechanical properties and can be used in large-span, high-rise, heavy-load, and thin-walled structures. If SFHSC is used in structures that bear dynamic loads, the effect will be more significant.

Many studies [13] have used concrete-notched beams to explore the crack growth of concrete beam specimens. The fracture properties of conventional cracked concretes are commonly related to the relative notch depth [22]. If the notch changes the net section strength $\left(\sigma_{\text {net }}\right)$ of the material, then the material can be considered to have notch sensitivity [23]. Therefore, notch sensitivity means that the value of $\sigma_{\text {net }}$ may be reduced due to the existence of notches. Commonly, materials without notch sensitivity can be directly analyzed using classical mechanics. Notch-sensitive materials must be analyzed using the principles of fracture mechanics. There is a microcrack zone at the tip of a concrete crack. It is generally believed that a metal elastoplastic fracture mechanics model such as the J-integral model is not suitable for concrete. Hillerborg proposed a fictitious crack model (FCM) [24,25] that eliminated the influence of metal fracture mechanics conceptually, and created a new idea for the study of concrete nonlinear fractures. Hardened cement mortar is generally considered to be a notch sensitive material. Hu, Y. and Wang, J. et al. [26,27] showed that steel fiber concrete displayed notch sensitivity. In this study, we studied the notch sensitivity of SFHSC using three-point bending tests of notched beams. By adding steel fiber to the concrete matrix, the strength and toughness of concrete will be improved, especially for high-strength concrete [28].

A large number of studies have shown that a variety of fibers can enhance the fracture properties of concrete. Zinnur Çelik et al. [29,30] revealed that polypropylene-fiberreinforced concrete had high impact resistance and fracture energy. Zongcai Deng [31] investigated the fracture and fatigue properties of carbon-fiber-reinforced concrete (CFRC) through three-point bending tests. The results proved that the threshold of the fracture parameters and the ability to resist the bending fatigue load were greater for CFRC than for ordinary concrete. However, the cost of carbon, polypropylene, and other fibers compared to steel fibers is too high for use in practical engineering.

Since it has been proven that many factors affect the mechanical properties and fracture behavior of concrete, research and testing should be implemented for Steel fiber parameters, test methods and dimensional variables of test pieces, etc. [32-36] Kazemi et al. [37] studied the fracture behavior of steel fiber reinforced high-strength concrete (SFRHSC), and used the work of fracture method (WFM) and the size effect method (SEM) to measure the fracture parameters. The results showed that on enhancing the content of steel fibers, the fracture energy in WFM and SEM increased; however, the increment in WFM was more significant, with HSC becoming more ductile for introducing the fibers. Zhang et al. [38] used a servo hydraulic press and a drop-hammer impact device to perform the three-point bending test on a steel fiber concrete (SFRC) notched beam. As the loading rate increased, the fracture energy and peak load were observed to increase significantly. However, SFHSC with different strengths may be used in designing large structures. Based on the reinforcement mechanism theory, of steel fiber reinforced concrete and in consideration of the influence of crack subcritical propagation on fracture behaviors, we establish some parameter calculation models of SFHSC suitable for different strengths, that are conducive to the calculation and analysis of large structures. Therefore, it is essential to systematically explore the fracture performance of SFHSC, so as to identify more convenient and accurate calculation methods.

The test is mainly aimed at examining the influence of the steel fiber volume ratio, steel fiber type, relative notch depth, and other factors on the fracture toughness $\left(\mathrm{K}_{\mathrm{IC}}\right)$ and fracture energy $\left(\mathrm{G}_{\mathrm{F}}\right)$ of SFHSC. To this end, rational calculation models for the fracture behaviors of SFHSC are developed. 


\section{Materials and Methods}

\subsection{Material}

In the test mixture, the fundamental material, PO 42.5 ordinary Portland cement, with a 28-day strength greater than 42.5 was used. The standard water/cement ratio of SFHSC was 0.3 , and the sand ratio was 0.34 . The coarse aggregate was composed of crushed limestone with a maximum particle size of $20 \mathrm{~mm}$. The fine aggregate was medium coarse river sand with a fineness modulus of 3.39. According to the water/cement ratio of the SHFSC, in this test, a 1\% FDN-1 superplasticizer with a strong dispersing effect on cement was mixed with cement through daily drinking water. The steel fiber types were milled steel fiber (MF), bow steel fiber (BF), and shear corrugated steel fiber (SF). The types of steel fiber are shown in Figure 1. The material properties of the steel fiber types are shown in Table 1.

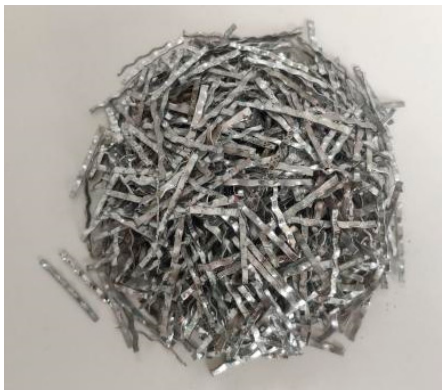

(a)

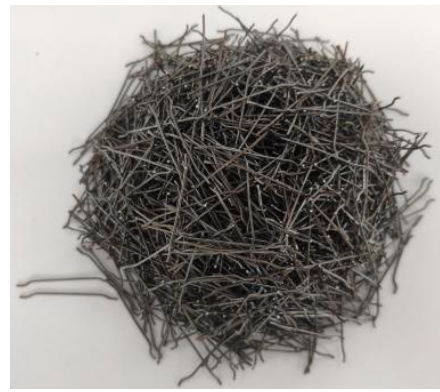

(b)

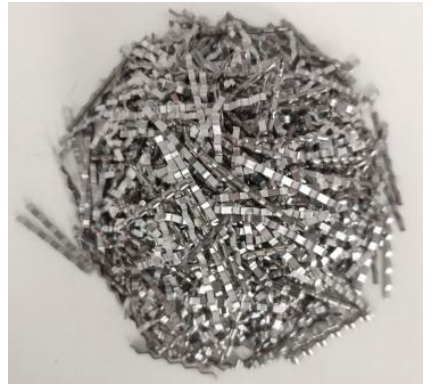

(c)

Figure 1. Sketch of the specimen shape and dimension. (a) Milled steel fiber; (b) Bow steel fiber; (c) Shear corrugated steel fiber.

Table 1. Material properties of the steel fiber types.

\begin{tabular}{cccc}
\hline Steel Fiber Type & $\begin{array}{c}\text { Average Length } \\
\mathbf{1}_{\mathbf{f}} / \mathbf{m m}\end{array}$ & $\begin{array}{c}\text { Equivalent Diameter } \\
\mathbf{d}_{\mathbf{f}} / \mathbf{m m}\end{array}$ & $\begin{array}{c}\text { Aspect Ratio } \\
\mathbf{1}_{\mathbf{f}} / \mathbf{d}_{\mathbf{f}}\end{array}$ \\
\hline Milled steel fiber & 31.312 & 0.9936 & 31.51 \\
Bow steel fiber & 32.426 & 0.5648 & 57.40 \\
Shear corrugated & 30.529 & 0.5592 & 54.60 \\
steel fiber & & & \\
\hline
\end{tabular}

\subsection{Mix Design}

The test was designed according to the test method of the China Engineering Construction Standardization Association $[39,40]$. The base concrete mix ratio was water/cement/fine aggregate/coarse aggregate/superplasticizer = 146:487:618:1199:4.87. The SFHSC increased water consumption by $10 \mathrm{~kg}$ from the reference group concrete to the fiber group concrete. According to the requirements of the specification $[39,40]$, SFHSC increased water consumption by $10 \mathrm{~kg}$ from the reference group concrete to the fiber group concrete. For every $0.5 \%$ increment in $\rho_{f}$, the water consumption increased by $8 \mathrm{~kg}$. Six types of samples with $0 \%, 0.5 \%, 1.0 \%, 1.5 \%, 2.0 \%$, and $2.5 \%$ steel fibers in the $\rho_{f}$ were prepared.

In order to eliminate the influence of the strength variation of the base concrete on the fracture behavior test results of the SFHSC, ordinary HSC with the same mix ratio but without steel fiber was used as the comparison test specimen. The mix proportions of SFHSC and HSC are shown in Table 2. 
Table 2. Mix proportions of SFHSC and HSC (unit, $\mathrm{kg} / \mathrm{m}^{3}$ ).

\begin{tabular}{|c|c|c|c|c|c|c|c|}
\hline Mix No. & Cement & Water & $\begin{array}{l}\text { W/C } \\
\text { Ratio }\end{array}$ & $\begin{array}{c}\text { Fine } \\
\text { Aggregate }\end{array}$ & $\begin{array}{c}\text { Coarse } \\
\text { Aggregate }\end{array}$ & $\begin{array}{l}\text { Superplasticizer } \\
\text { (FDN-1) }\end{array}$ & $\rho_{f}$ \\
\hline MF00 & 487 & 146 & 0.3 & 618 & 1199 & 4.87 & 0.0 \\
\hline MFT05-0 & 520 & 156 & 0.3 & 710 & 1065 & 5.20 & 0.0 \\
\hline MFT05 & 520 & 156 & 0.3 & 710 & 1065 & 5.20 & 39.3 \\
\hline MFT10-0 & 547 & 164 & 0.3 & 696 & 1044 & 5.47 & 0.0 \\
\hline MFT10 & 547 & 164 & 0.3 & 696 & 1044 & 5.47 & 78.6 \\
\hline MFT15-0 & 573 & 172 & 0.3 & 682 & 1023 & 5.73 & 0.0 \\
\hline MFT15 & 573 & 172 & 0.3 & 682 & 1023 & 5.73 & 117.9 \\
\hline MFT20-0 & 600 & 180 & 0.3 & 668 & 1002 & 6.00 & 0.0 \\
\hline MFT20 & 600 & 180 & 0.3 & 668 & 1002 & 6.00 & 157.2 \\
\hline MFT25-0 & 627 & 188 & 0.3 & 654 & 981 & 6.27 & 0.0 \\
\hline MFT25 & 627 & 188 & 0.3 & 654 & 981 & 6.27 & 196.5 \\
\hline BFT15-0 & 573 & 172 & 0.3 & 682 & 1023 & 5.73 & 0.0 \\
\hline BFT15 & 573 & 172 & 0.3 & 682 & 1023 & 5.73 & 117.9 \\
\hline SFT15-0 & 573 & 172 & 0.3 & 682 & 1023 & 5.73 & 0.0 \\
\hline SFT15 & 573 & 172 & 0.3 & 682 & 1023 & 5.73 & 117.9 \\
\hline
\end{tabular}

Note: The first two letters indicate the type of steel fiber. T indicates that the specimen is a three-point bending specimen. -0 indicates the SHFSC comparison test specimen. MFT00 represents the reference group HSC.

\subsection{Specimen Preparation}

An SFHSC notch beam specimen is shown in Figure 2, in which the specimen was designed as a cuboid of $100 \mathrm{~mm} \times 100 \mathrm{~mm} \times 515 \mathrm{~mm}$, and the beam span (S) was $400 \mathrm{~mm}$. The notch was located at the side of the pouring face of the test piece. The incision was made using a high-speed concrete cutting machine, and the width of the saw gap was around $3 \mathrm{~mm}$. Furthermore, the cut depths $\mathrm{a}_{0}$ were $40 \mathrm{~mm}$ and $50 \mathrm{~mm}$. The relative notch depth of the prefabricated cracks of the specimen included $\mathrm{a}_{0} / \mathrm{h}=0.4$ and 0.5 . The SFHSC design-strength grade was FC50.
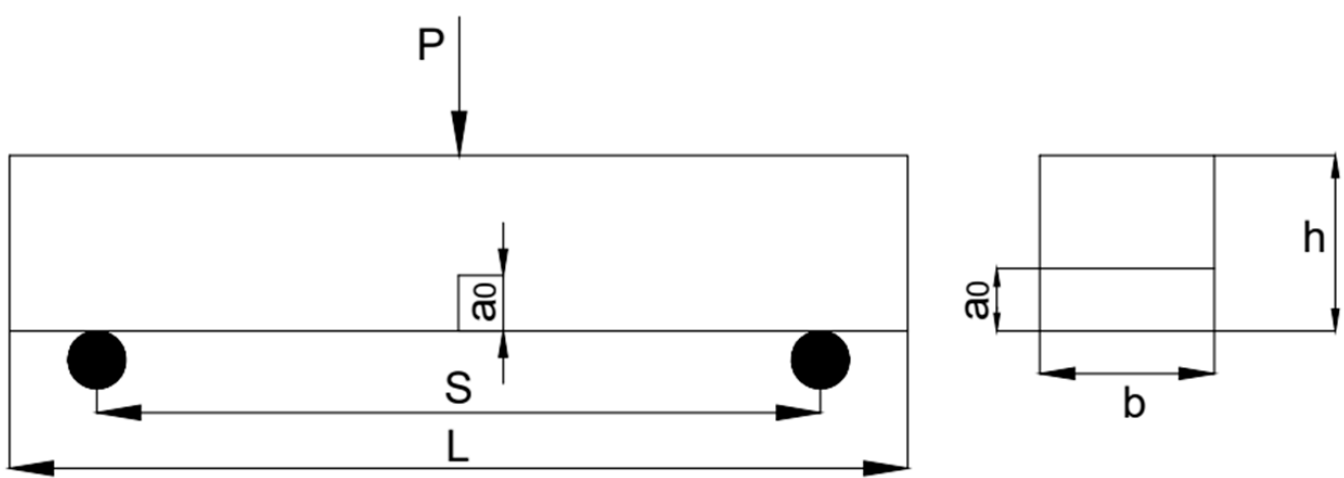

Figure 2. Sketch of the specimen shape and dimension.

The test materials were appropriately cleaned by removing the impurities before fabricating the SFHSC specimens. The SFHSC specimens were formed using a mixer to mix the concrete, and a vibration table was used for forming. The specimens were cured for 28 days at a temperature of $20 \pm 2{ }^{\circ} \mathrm{C}$ and a relative humidity of no less than $95 \%$. The test age was $60-70 \mathrm{~d}$. The mixed concrete and processed SFHSC specimens are shown in Figure $3 \mathrm{a}, \mathrm{b}$. 


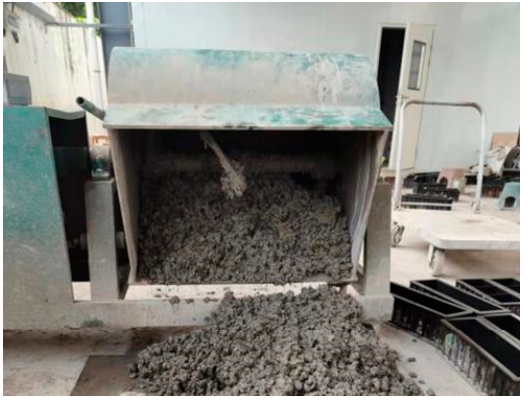

(a)

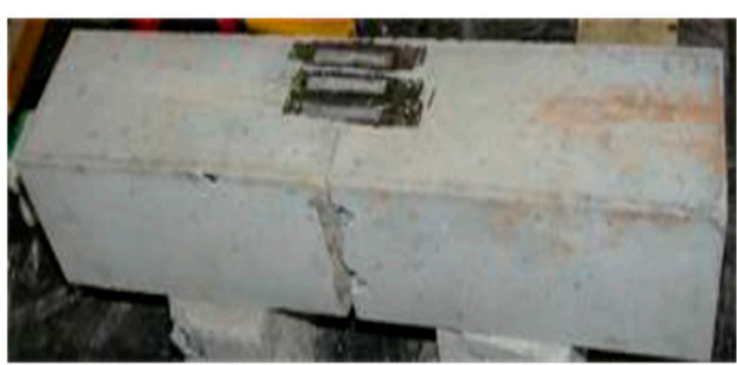

(b)

Figure 3. Mixed concrete (a) and processed SFHSC specimen (b).

\subsection{Test Method}

\subsubsection{Three-Point Bending Test Procedure}

The three-point bending tests (TPBTs) were carried out on a $2000 \mathrm{kN}$ universal testing machine (Figure 4). In the test, cylindrical springs with greater stiffness were used to reinforce the test machine and ensure that any additional deformation energy generated by the sudden unloading of the testing machine was absorbed at the moment of failure of the test specimen; therefore, the test process was reliable and stable. During the test, the beams were arranged above the two supporting points. The load was applied downwards, directly above the midpoint of the two support points, and measured by a load sensor in the range of 0 to $30 \mathrm{kN}$. In addition, an extensometer was used on the lower surface of the beam to obtain the crack opening displacement (CMOD). The test adopted a continuous loading method, and used a computer data collection system to realize automatic data collection. The collection rate used different collection frequencies according to the type of component. Among these, the value of the HSC component was 2 times/s, whereas the SFHSC component had a value of 1 time/s. At the same time, the load CMOD (P-CMOD) and load deflection (P- $\delta$ ) were analyzed. According to the curve, and combined with the observation of the test phenomena in the test process, the fracture behavior of SHFSC was qualitatively and quantitatively analyzed. The schematic diagram of the TPBTs loading device is shown in Figure 5.

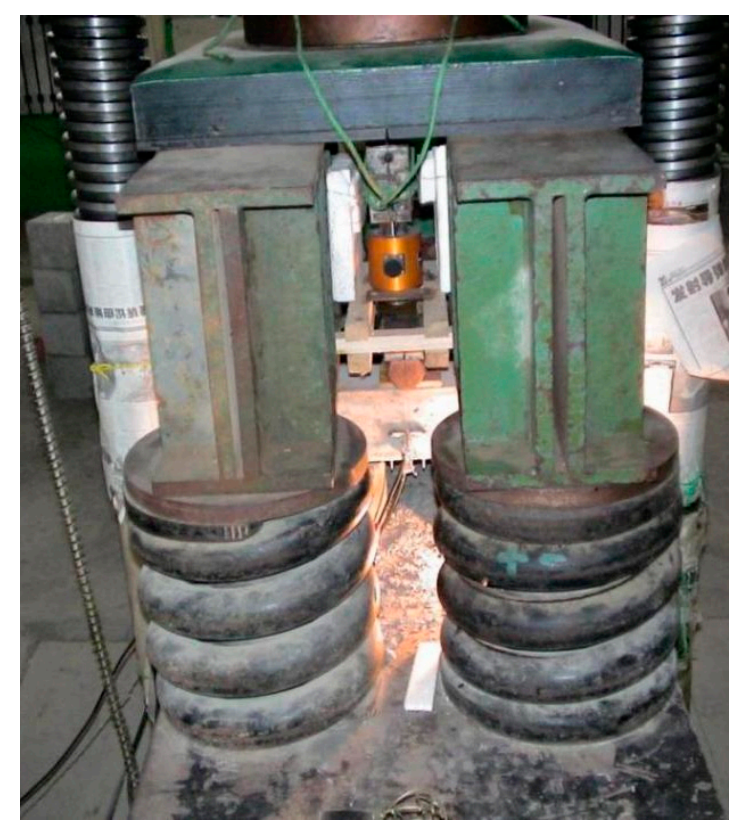

Figure 4. The photo of three-point bending test machine. 


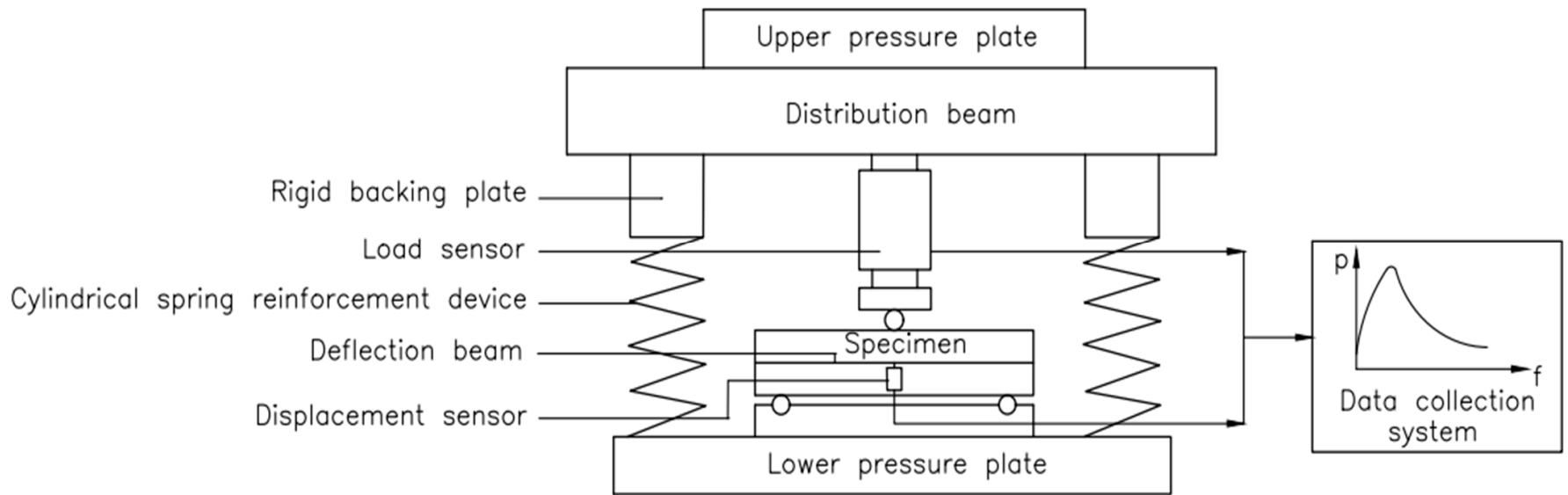

Figure 5. The schematic diagram of the TPBTs loading device.

\subsubsection{Test Parameter Calculation}

In this test, the fracture toughness was calculated using ASTM Formulas (1) and (2) as follows:

$$
\begin{gathered}
K_{I C}=\frac{P_{\max } S}{t h^{3 / 2}} f\left(\frac{a_{e}}{h}\right) \\
f\left(\frac{a_{e}}{h}\right)=2.9\left(\frac{a_{e}}{h}\right)^{\frac{1}{2}}-4.6\left(\frac{a_{e}}{h}\right)^{\frac{3}{2}}+21.8\left(\frac{a_{e}}{h}\right)^{\frac{5}{2}}-37.6\left(\frac{a_{e}}{h}\right)^{\frac{7}{2}}+38.7\left(\frac{a_{e}}{h}\right)^{\frac{9}{2}}
\end{gathered}
$$

where $P_{\max }$ is the peak load of the three-point bending beam, $S$ is the span between the three-point bending beam supports, $b$ is the thickness of the test specimen, and $a_{\mathrm{e}}$ is the equivalent crack length.

Its value is an iterative calculation according to the $\mathrm{F}_{\max }$ and $C M O D_{C}$ obtained from the p-CMOD curve measured in the test, and it is calculated according to Equation (3) as follows:

$$
\begin{gathered}
C M O D_{C}=\frac{6 P_{\operatorname{mas}} S a_{e}}{t h^{2} E} f_{1}\left(\frac{a_{e}}{h}\right) \\
f_{1}\left(\frac{a_{e}}{h}\right)=1.45-2.18 \frac{a_{e}}{h}+13.71\left(\frac{a_{e}}{h}\right)^{2}-5.96\left(\frac{a_{e}}{h}\right)^{3}-36.9\left(\frac{a_{e}}{h}\right)^{4}+70.7\left(\frac{a_{e}}{h}\right)^{5}
\end{gathered}
$$

where $E$ is the elastic modulus, and its value is the measured value of the concrete elastic modulus of SFHSC, and the comparison group obtained in the experiment; $C M O D_{C}$ is the critical crack mouth opening displacement.

The calculation Formula (5) of the fracture energy $G_{F}$ is [25] as follows:

$$
G_{F}=\frac{W}{A_{\text {lig }}}=\frac{W_{0}+\left(g S+2 P_{1}\right) \delta_{0}}{b\left(h-a_{0}\right)}
$$

where $A_{\text {lig }}$ is the area of the fractured ligament perpendicular to the direction of tensile stress, $g$ is the linear distributed load of the beam's dead weight, $a_{0}$ is the length of the prefabricated crack of the test specimen, and $\delta_{0}$ is the ultimate deflection of the three-point bending beam.

\section{Results and Discussions}

The three-point bending test results for the specimens are shown in Table 3. 
Table 3. TPBT results for fracture properties of SFHSC and HSC specimens.

\begin{tabular}{|c|c|c|c|c|c|c|c|c|}
\hline Mix No. & $\rho_{f} / \%$ & $\mathrm{a} / \mathrm{h}_{0}$ & $\begin{array}{c}\text { Peak Load } \\
P_{\max } / \mathbf{k N}\end{array}$ & $\begin{array}{c}\text { Subcritical } \\
\text { Crack } \\
\text { Growth } \\
\text { Length } \\
\Delta \mathrm{a} / \mathrm{mm}\end{array}$ & $\mathrm{K}_{\mathrm{IC}} / \mathrm{MPa} \cdot \mathrm{m}^{1 / 2}$ & $\mathrm{G}_{\mathrm{F}} / \mathrm{N} \cdot \mathbf{m}^{-1}$ & $\mathrm{CMOD}_{\mathrm{C}} / \mathrm{mm}$ & CTOD $_{\mathrm{C}} / \mathrm{mm}$ \\
\hline MFT00-4 & 0.0 & 0.4 & 3.1555 & 34.25 & 2.0679 & 117.9977 & 0.0903 & 0.0343 \\
\hline MFT00-5 & 0.0 & 0.5 & 2.2942 & 23.34 & 1.8981 & 116.0086 & 0.0852 & 0.0291 \\
\hline MFT05-4 & 0.5 & 0.4 & 3.1915 & 31.68 & 2.2890 & 290.7975 & 0.0980 & 0.0328 \\
\hline MFT05-5 & 0.5 & 0.5 & 1.7311 & 30.73 & 1.7531 & 339.9776 & 0.1039 & 0.0271 \\
\hline MFT05-0-4 & 0.0 & 0.4 & 3.4333 & 20.97 & 1.7222 & 122.8843 & 0.0609 & 0.0212 \\
\hline MFT05-0-5 & 0.0 & 0.5 & $*$ & * & $*$ & $*$ & * & * \\
\hline MFT10-4 & 1.0 & 0.4 & 3.6135 & 30.98 & 2.6288 & 614.5192 & 0.1184 & 0.0372 \\
\hline MFT10-5 & 1.0 & 0.5 & 2.8067 & 29.72 & 3.1170 & 914.7674 & 0.1731 & 0.0834 \\
\hline MFT10-0-4 & 0.0 & 0.4 & 2.6569 & 25.01 & 1.7615 & 97.4028 & 0.0639 & 0.0223 \\
\hline MFT10-0-5 & 0.0 & 0.5 & 1.4566 & 29.50 & 1.6891 & 86.2186 & 0.0887 & 0.0332 \\
\hline MFT15-4 & 1.5 & 0.4 & 3.9438 & 33.53 & 4.8897 & 1023.5237 & 0.2053 & 0.0736 \\
\hline MFT15-5 & 1.5 & 0.5 & 3.2958 & 31.84 & 4.0708 & 1260.7336 & 0.2885 & 0.0976 \\
\hline MFT15-0-4 & 0.0 & 0.4 & 3.4175 & 31.72 & 1.7726 & 104.6507 & 0.0628 & 0.0290 \\
\hline MFT15-0-5 & 0.0 & 0.5 & 2.1774 & 26.63 & 1.8625 & 133.7628 & 0.0849 & 0.0265 \\
\hline MFT20-4 & 2.0 & 0.4 & 4.7587 & 12.56 & 6.2200 & 1924.8270 & 0.3106 & 0.1054 \\
\hline MFT20-5 & 2.0 & 0.5 & 3.3240 & 37.52 & 5.4453 & 1365.6888 & 0.3413 & 0.1199 \\
\hline MFT20-0-4 & 0.0 & 0.4 & 3.3998 & 24.80 & 1.8742 & 157.4831 & 0.0683 & 0.0216 \\
\hline MFT20-0-5 & 0.0 & 0.5 & 2.5554 & 23.77 & 1.7792 & 135.7786 & 0.0888 & 0.0269 \\
\hline MFT25-4 & 2.5 & 0.4 & 6.3708 & 43.43 & 8.3826 & 2842.1893 & 0.4394 & 0.1552 \\
\hline MFT25-5 & 2.5 & 0.5 & 5.0915 & 40.35 & 7.6635 & 2409.6982 & 0.5298 & 0.1833 \\
\hline MFT25-0-4 & 0.0 & 0.4 & 2.9207 & 23.38 & 1.7326 & 118.0064 & 0.0680 & 0.0289 \\
\hline MFT25-0-5 & 0.0 & 0.5 & 2.2196 & 25.03 & 1.7517 & 95.2540 & 0.0820 & 0.0253 \\
\hline BFT15-4 & 1.5 & 0.4 & 9.7843 & 61.05 & 29.5033 & $11,217.1258$ & 2.5063 & 0.8449 \\
\hline BFT15-0-4 & 0.0 & 0.4 & 3.2905 & 25.37 & 2.0203 & 120.6065 & 0.0719 & 0.0239 \\
\hline SFT15-4 & 1.5 & 0.4 & 4.0623 & 31.99 & 3.7856 & 1825.1208 & 0.2512 & 0.0480 \\
\hline SFT15-0-4 & 0.0 & 0.4 & 3.0870 & 27.35 & 2.1178 & 117.0248 & 0.0803 & 0.0250 \\
\hline
\end{tabular}

\subsection{Fracture Toughness}

3.1.1. The Effect of $\rho_{f}$ on the Fracture Toughness of SFHSC

The influence of $\rho_{f}$ on the $\mathrm{K}_{\mathrm{IC}}$ of the SHFSC specimens under the conditions of the relative depth of the two notches is shown in Figure 6a. In addition to the SFHSC specimens with $\rho_{f}=0.5 \%$ and $\mathrm{a}_{0} / \mathrm{h}=0.5$, the $\mathrm{K}_{\mathrm{IC}}$ of SFHSC was improved to different degrees compared to HSC. The $\mathrm{K}_{\mathrm{IC}}$ values of the SFHSC specimens show a good increasing trend with an increase in $\rho_{f}$. For every $0.5 \%$ increment in $\rho_{f}$, the average increase in the $\mathrm{K}_{\mathrm{IC}}$ value were as follows: when $\mathrm{a}_{0} / \mathrm{h}=0.4, \mathrm{~K}_{\mathrm{IC}}$ increases by $40.7 \%$; when $\mathrm{a}_{0} / \mathrm{h}=0.5, \mathrm{~K}_{\mathrm{IC}}$ increases by $45.7 \%$. According to the results, when $\rho_{f}$ reaches a certain value, the addition of steel fiber can increase the $\mathrm{K}_{\mathrm{IC}}$ of SFHSC. Kazemi et al. [37] also obtained similar results. 


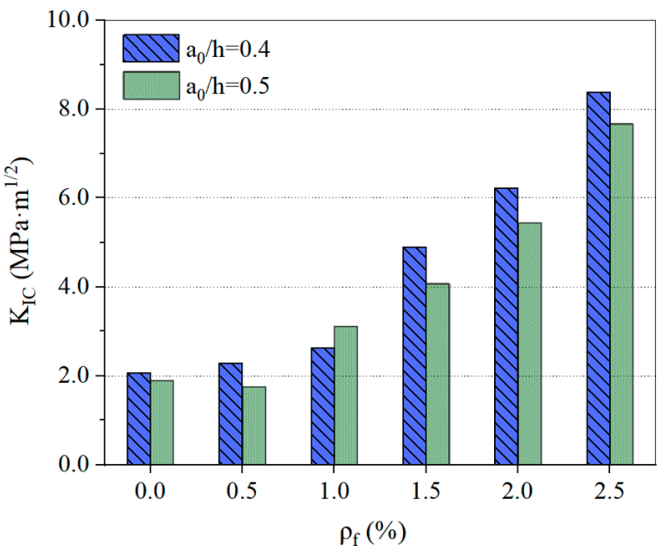

(a)

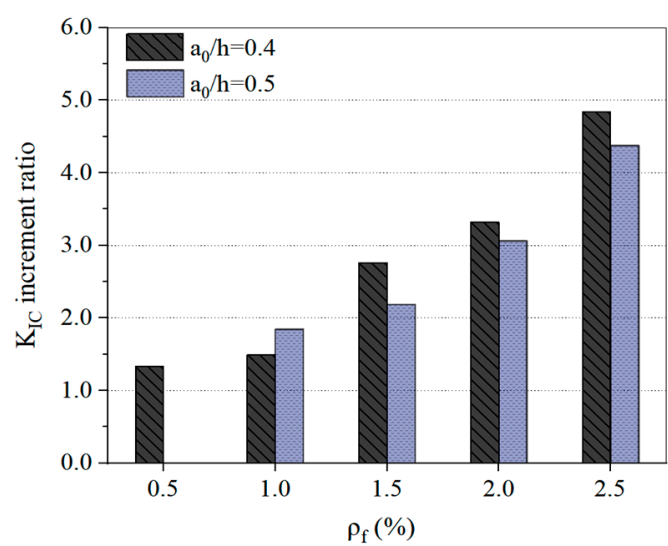

(b)

Figure 6. Influence of $\rho_{f}$ on the $\mathrm{K}_{\mathrm{IC}}(\mathbf{a})$ and $\mathrm{K}_{\mathrm{IC}}$ increment ratio (b) of SFHSC.

Figure $6 \mathrm{~b}$ shows the effect of $\rho_{f}$ on the $\mathrm{K}_{\mathrm{IC}}$ increment ratio of the SFHSC specimens. It can be seen that there are no test data for $\mathrm{K}_{\mathrm{IC}}$ due to the $\rho_{f}=0.5 \%$ and $\mathrm{a}_{0} / \mathrm{h}=0.5$ comparison group specimen variation; all the other $\mathrm{K}_{\mathrm{IC}}$ increment ratio values are greater than 1. Moreover, the value of the $\mathrm{K}_{\mathrm{IC}}$ increment ratio also increases to varying degrees as $\rho_{f}$ increases. Regarding the variation range of the increment ratio, when $\mathrm{a}_{0} / \mathrm{h}=0.4$, the increment ratio values are between 1.33 and 4.84 , and the average increment ratio value is 2.75. When $\mathrm{a}_{0} / \mathrm{h}=0.5$, the increment ratio values are between 1.85 and 4.38 , and the average increment ratio value is 2.87 .

Figure 7a,b demonstrates the comparison of the failure modes of the SFHSC specimens with $\rho_{f}$ for two relative notch depths. The crack propagation of the SFHSC specimen is noted to be tortuous, and the crack exhibits multi-point cracking. Moreover, on increasing the fiber volume fraction, the crack propagation of the SFHSC specimen becomes more complex.

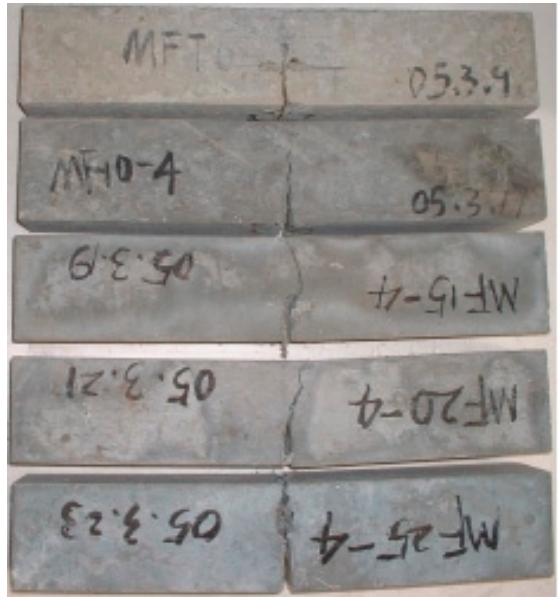

(a)

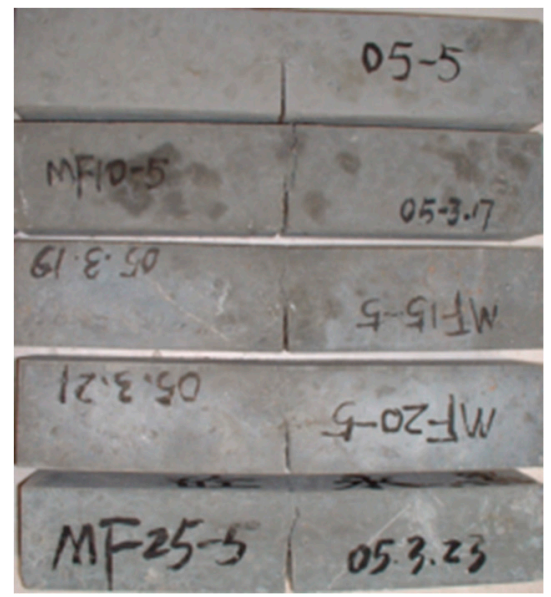

(b)

Figure 7. Comparison of crack face failure mode between SFHSC beams reinforced with different $\rho_{f}$ at $\mathrm{a}_{0} / \mathrm{h}=0.4(\mathbf{a})$ and $\mathrm{a}_{0} / \mathrm{h}=0.5(\mathbf{b})$.

A comparison of typical load deflection (P- $\delta$ ) curves of SFHSC specimens with different $\rho_{f}$ under the conditions of two relative opening depths is shown in Figure $8 \mathrm{a}, \mathrm{b}$. The peak loads of the curves in the figures from bottom to top are MF05, MF10, MF15, MF20, and MF25. It can be observed that before the initial crack of the SHFSC specimen, the load increases with an increase in the deformation, and $\rho_{f}$ has no significant effect on the curve. As the load continues to increase, the microscopic cracks appear in the concrete matrix. The cracks continue to grow until the appearance of macro cracks, and the SHFSC specimen 
is in the elastoplastic stage. In the process of gradual pull-out, the steel fiber connects the concrete across the crack. It mainly controls the propagation of cracks in the concrete matrix and limits the crack width. After the concrete matrix cracks, the cracks are bridged [41,42]. With an increase in $\rho_{f}$, the number of fibers across the crack increases correspondingly, and the ability to transfer stress is also relatively improved. If the nonlinear development stage is longer, the development of microcracks in the fracture process area is found to be relatively sufficient, and the absorbed external load energy increases accordingly. It suggests that the fracture performance can be enhanced with an increase of the peak load and the ultimate deflection.

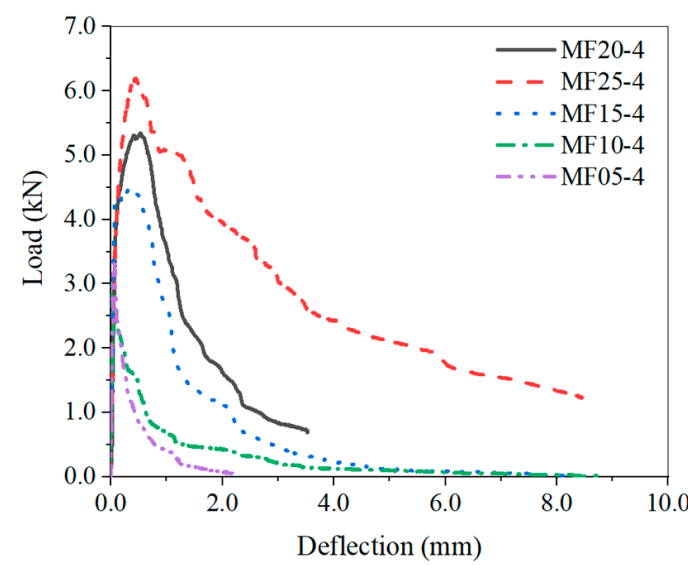

(a)

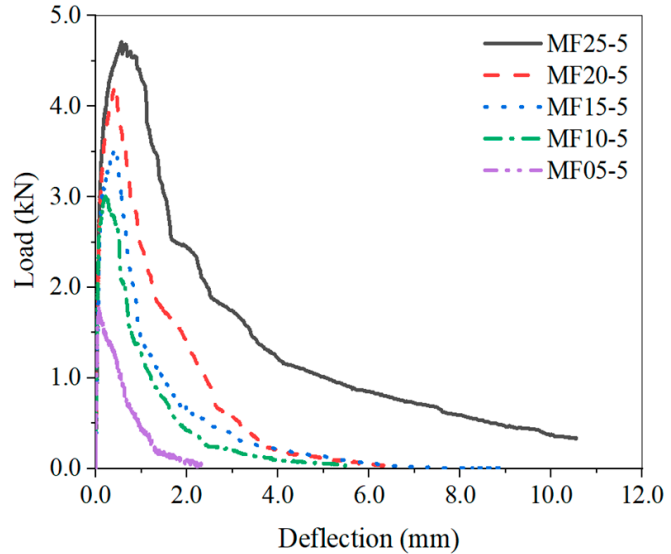

(b)

Figure 8. Typical load deflection curves of the SFHSC beams with $\mathrm{a}_{0} / \mathrm{h}=0.4(\mathbf{a})$ and $\mathrm{a}_{0} / \mathrm{h}=0.5$ (b).

\subsubsection{Effect of Steel Fiber Type on Fracture Toughness of SFHSC}

Due to the different effects of steel fiber types and steel fiber lengths on the fracture behavior of SFHSC specimens we introduce, in this study, the concept of characteristic fracture parameters, defined as the SFHSC fracture parameter/characteristic content of steel fiber. The characteristic $\mathrm{K}_{\mathrm{IC}}$ and increment ratio of the same HSC matrix and different steel fiber types of SFHSC specimens are shown in Figure $9 \mathrm{a}, \mathrm{b}$ when $\rho_{f}=1.5 \%$ and $\mathrm{a}_{0} / \mathrm{h}=0.4$. It indicates that the BF improves the $\mathrm{K}_{\mathrm{IC}}$ most significantly, followed by the MF. The characteristic $\mathrm{K}_{\mathrm{IC}}$ values of the BF are 3.62 and 7.41 times those of the MF and SF, respectively, and the $\mathrm{K}_{\mathrm{IC}}$ increment ratios are 3.17 and 7.77 times those of the $\mathrm{MF}$ and $\mathrm{SF}$, respectively.

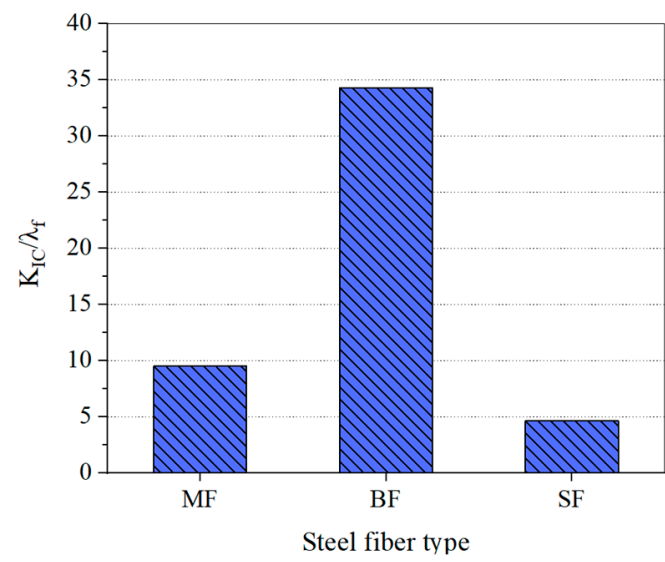

(a)

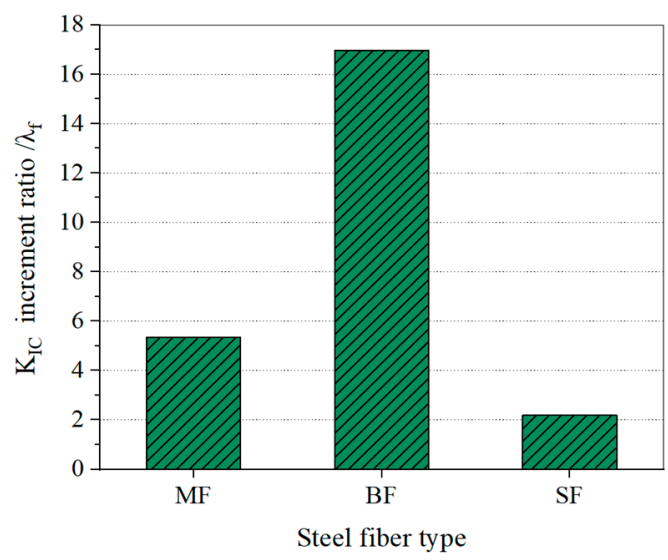

(b)

Figure 9. Influence of steel fiber types on the $\mathrm{K}_{\mathrm{IC}}(\mathbf{a})$ and $\mathrm{K}_{\mathrm{IC}}$ increment ratio (b) of SFHSC. 
Similar to the results of this study, those by X W Wang et al. [43] show that the types of steel fiber deliver a greater impact on the fracture toughness of Steel-Fiber-Reinforced Concrete. The test results demonstrate that Bekaert-type fiber has a better performance in improving the fracture toughness.

The typical load deflection curves of SFHSC for different steel fiber types are shown in Figure 10. In the early stage of loading, due to the synergistic effect of the steel fiber and matrix concrete, the load-deflection curves of SFHSC specimens with different steel fiber types are not found to be significantly different. As the load increases, cracks appear in the concrete matrix. Owing to the different steel fiber types, the load-deflection curves are different. The BF and SF have a greater increment effect on high-strength concrete than MF. However, the BF high-strength concrete exhibits a weak stress-strengthening phenomenon in the tests, and exhibits metal stress-strain characteristics to some extent. In addition, the occurrence of the second peak may be related to the spalling of large aggregates, and the reinforcement of the BF should be the main reason for the stress strengthening. Although the process requires a certain amount of energy, it also leads to the release of stress and strain at the fracture area, which weakens the toughening effect of the fiber. In general, the width of the zone is related to the half-length of the fiber length and the maximum particle size of the aggregate used. The peak load and ultimate deflection of SFHSC can be significantly increased by the BF, and the bearing capacity of SFHSC specimens after the peak can be significantly increased by the end hook of the BF. Test curve of BF15-4 is steeper and the descent section is gentler. Due to the significant deformation of the BF high-strength concrete beam, even if the deflection test dial indicator is adjusted during the loading process, it is still difficult to measure its ultimate deflection. However, this trend is sufficient to show that BF has significant advantages over other types of steel fibers for improving HSC fracture behavior. There is no significant difference in peak load performance between MF and sheared SF, but from the descending section of the typical test curve, it can be found that the toughening effect of SF is slightly better than that of MF.

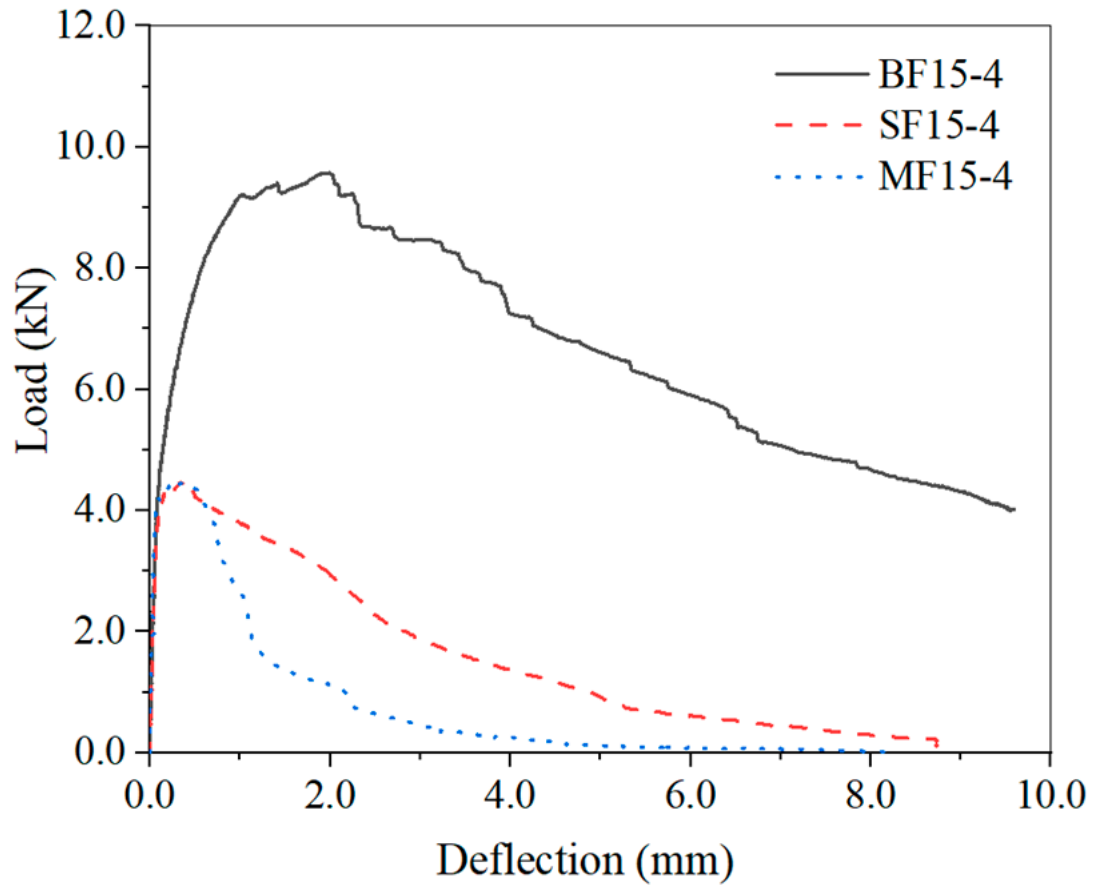

Figure 10. Typical load-deflection curves of SFHSC beam reinforced.

\subsubsection{The Influence of Incision Depth on Fracture Toughness of SFHSC}

Figure 11 reveals the comparison of the $\mathrm{K}_{\mathrm{IC}}$ ratios of the milled SFHSC, i.e., the comparison group and the reference group HSC specimens under the conditions of different $\rho_{f}$ corresponding mix ratios $\left(\mathrm{K}_{\mathrm{IC} 0.5} / \mathrm{K}_{\mathrm{IC} 0.4}\right)$. It shows that the $\mathrm{K}_{\mathrm{IC} 0.5} / \mathrm{K}_{\mathrm{IC} 0.4}$ values of the 
SFHSC specimens are all less than 1, and the average value is 0.92 , except for $\rho_{f}=1.0 \%$, which is the variation specimen. The value of $\mathrm{K}_{\mathrm{IC}}$ has a decreasing trend with an increase in the notch depth. With an increase in $\rho_{f}$, the value of $\mathrm{K}_{\mathrm{IC} 0.5} / \mathrm{K}_{\mathrm{IC} 0.4}$ has an increasing trend. The fracture toughness notch sensitivity gradually decreases. The value of $\mathrm{K}_{\mathrm{IC} 0.5} / \mathrm{K}_{\mathrm{IC} 0.4}$ fluctuates irregularly between 0.92 and 1.05 for the HSC specimens of the reference group and the comparison group of SFHSC. Its average value is 0.98 . According to the test data in this study, it can be inferred that SFHSC materials are notch sensitive, while HSC materials are notch insensitive.

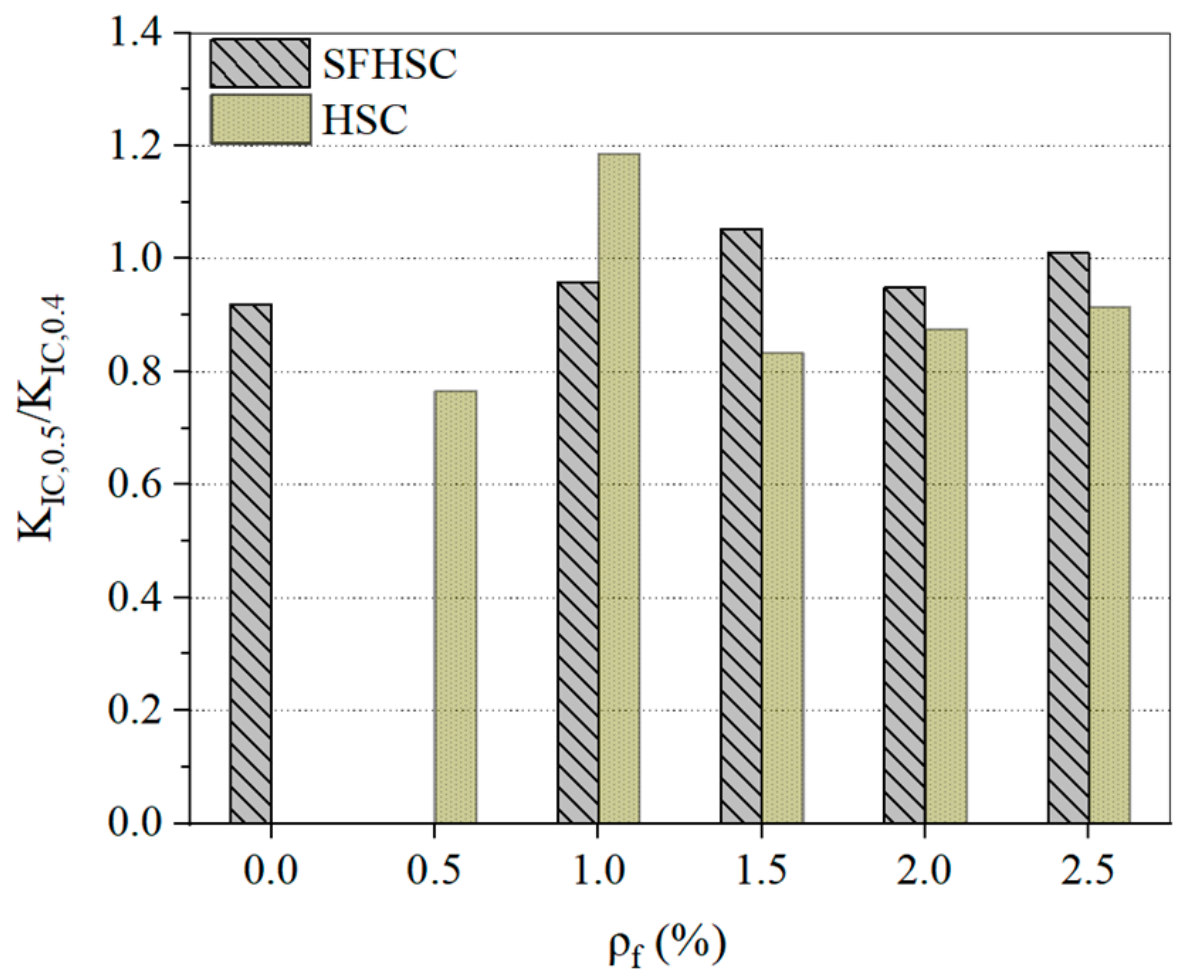

Figure 11. Influence of notch depth on the $\mathrm{K}_{\mathrm{IC}}$ of SFHSC and HSC.

\subsection{Fracture Energy}

\subsubsection{The Effect of $\rho_{f}$ on the Fracture Energy of SFHSC}

The fracture energy of concrete is one of the important parameters for understanding concrete properties and determining the design standards of large concrete structures [15]. Figure $12 \mathrm{a}, \mathrm{b}$ shows the effect of $\rho_{f}$ on the $\mathrm{G}_{\mathrm{F}}$ and $\mathrm{G}_{\mathrm{F}}$ increment ratio for SFHSC under different relative notch depth conditions. The results presented in Figure 12a reveal that no matter the depth of the incision changes, the addition of steel fiber can significantly increase $\mathrm{G}_{\mathrm{F}}$ compared with the reference HSC. Figure $12 \mathrm{a}$ shows that for every $0.5 \%$ increase in $\rho_{f}$, the average growth rate increases; when $\mathrm{a}_{0} / \mathrm{h}=0.4$, the $\mathrm{G}_{\mathrm{F}}$ increases by $78.39 \%$, and when $\mathrm{a}_{0} / \mathrm{h}=0.5, \mathrm{G}_{\mathrm{F}}$ increases by $59.92 \%$. As shown in Figure $12 \mathrm{~b}$, the $\mathrm{G}_{\mathrm{F}}$ increment ratio is greater than 1 with the addition of steel fiber. The $G_{F}$ increment ratio also shows a good increasing trend with an increase in $\rho_{f}$; especially, the increase in SFHSC with high fiber volume content is more significant. The change in the $\mathrm{G}_{\mathrm{F}}$ increment ratio for the SFHSC specimens is that, when $\mathrm{a}_{0} / \mathrm{h}=0.4$, the increment ratio values are between 2.36 and 24.08. When $\mathrm{a}_{0} / \mathrm{h}=0.5$, the increment ratio values are between 9.42 and 25.31 . In Figure 12b, the increment ratio values of the specimens with $\rho_{f}=1.0 \%$ and $\mathrm{a}_{0} / \mathrm{h}=0.5$ are clearly larger, which is due to the slight local damage caused by the HSC specimens during demolding. Therefore, the $\mathrm{G}_{\mathrm{F}}$ value of the HSC specimens in the comparison group is only $86.22 \mathrm{~N} \cdot \mathrm{m}^{-1}$. 


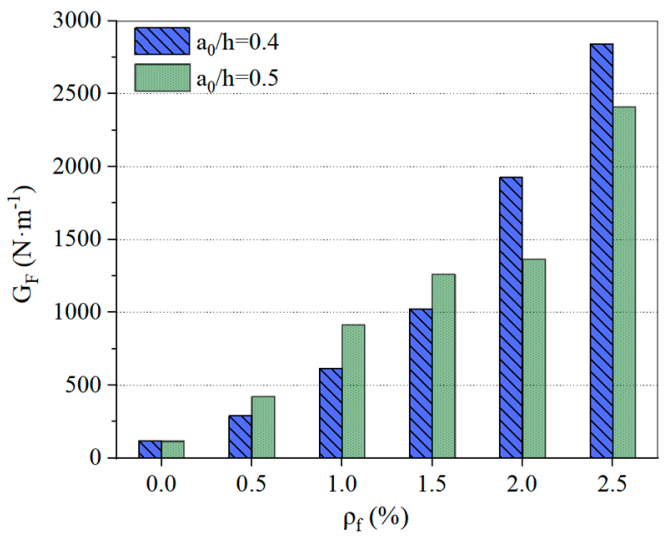

(a)

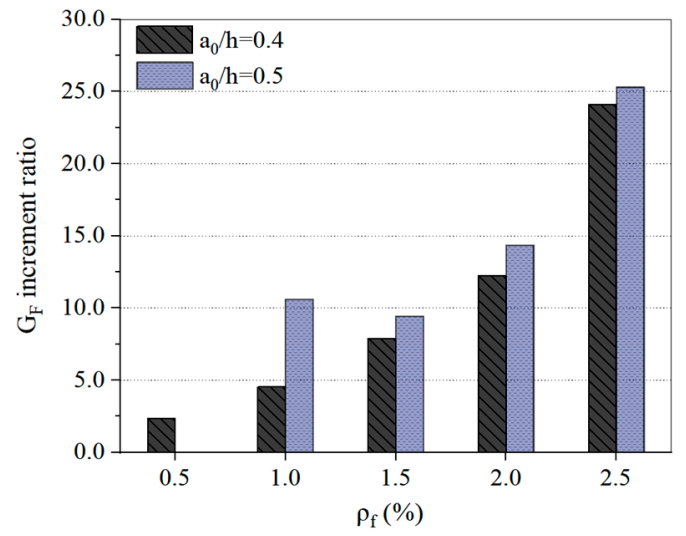

(b)

Figure 12. Influence of $\rho_{f}$ on the $\mathrm{G}_{\mathrm{F}}(\mathbf{a})$ and $\mathrm{G}_{\mathrm{F}}$ increment ratio (b) of SFHSC.

By comparing the test data with other relevant tests [16,37], it can be concluded that despite the differences in concrete mixtures, sample geometry and size between different studies, the fracture energy is greatly affected by the fiber volume ratio of SFHSC.

\subsubsection{Effect of Steel Fiber Type on the Fracture Energy of SFHSC}

For the specimens with the same pouring conditions and $\rho_{f}=1.5 \%$, the effects of different steel fiber types on the $\mathrm{G}_{\mathrm{F}}$ and the $\mathrm{G}_{\mathrm{F}}$ increment ratio of HSC are shown in Figure 13a,b. Regardless of the $\mathrm{G}_{\mathrm{F}}$ or the $\mathrm{G}_{\mathrm{F}}$ increment ratio, $\mathrm{BF}$ plays a significant role in the steel fiber, showing an excellent fiber-reinforced effect. The characteristic $\mathrm{G}_{\mathrm{F}}$ of $\mathrm{BF}$ is 6.57 and 5.85 times that of MF and SF, respectively, and its characteristic $\mathrm{G}_{\mathrm{F}}$ increment ratio is 7.06 and 5.67 times that of MF and SF, respectively.

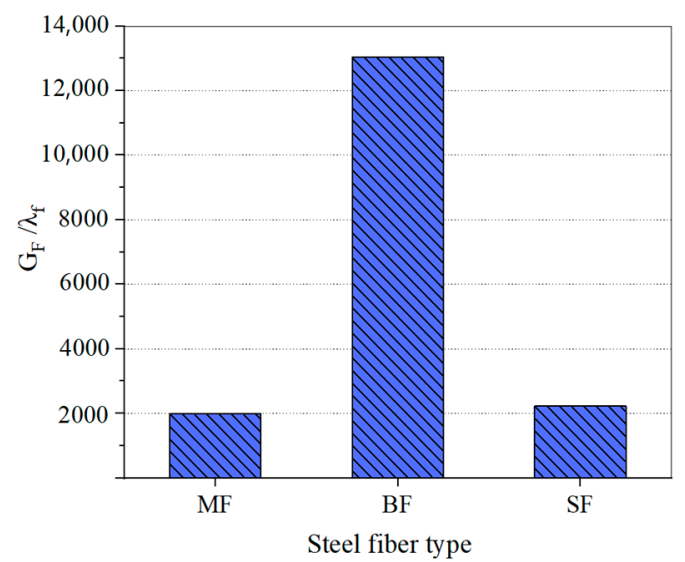

(a)

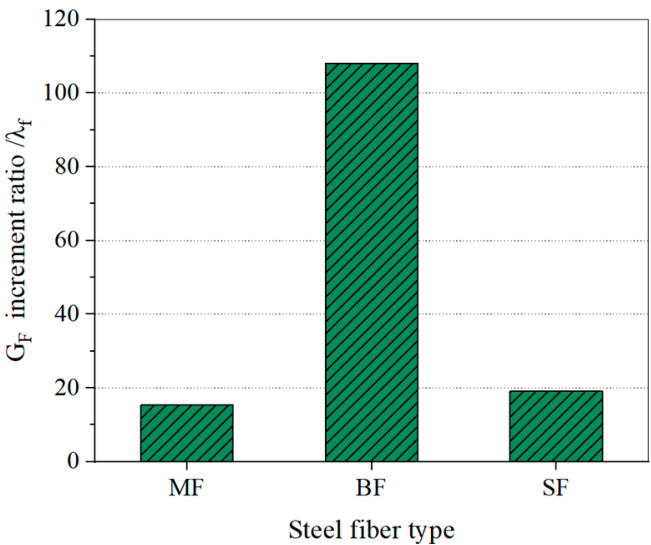

(b)

Figure 13. Influence of Steel Fiber Types on the $G_{F}(\mathbf{a})$ and $G_{F}$ Increment Ratio (b) of SFHSC.

\subsubsection{The Influence of Incision Depth on Fracture Energy of SFHSC}

The fracture energy ratio values of the specimens at $\mathrm{a}_{0} / \mathrm{h}=0.5$ and $\mathrm{a}_{0} / \mathrm{h}=0.4$ under different $\rho_{f}$ conditions $\left(\mathrm{G}_{\mathrm{F} 0.5} / \mathrm{G}_{\mathrm{F} 0.4}\right)$ are shown in Figure 14. According to the results in the figure, the $\mathrm{G}_{\mathrm{F} 0.5} / \mathrm{G}_{\mathrm{F} 0.4}$ values of the SFHSC specimens show a decreasing trend with an increase in $\rho_{f}$. The maximum and minimum values are 1.48 and 0.71 , respectively. The $\mathrm{G}_{\mathrm{F} 0.5} / \mathrm{G}_{\mathrm{F} 0.4}$ is greater than 1 when $\rho_{f}$ is less than $1.5 \%$, and when $\rho_{f}$ is greater than $1.5 \%$, the $\mathrm{G}_{\mathrm{F} 0.5} / \mathrm{G}_{\mathrm{F} 0.4}$ is less than 1. A notch strengthening phenomenon was observed for SFHSC with an increase in $\rho_{f}$. However, the changes in the values of $\mathrm{G}_{\mathrm{F} 0.5} / \mathrm{G}_{\mathrm{F} 0.4}$ of HSC specimens under different $\rho_{f}$ conditions have no obvious regularity, which means that a change in $\rho_{f}$ has no effect on the $\mathrm{G}_{\mathrm{F} 0.5} / \mathrm{G}_{\mathrm{F} 0.4}$. There are few studies that investigate the effect of notch 
depth changes on the $\mathrm{G}_{\mathrm{F}}$ of SFHSC; therefore, it is not possible to make a further horizontal comparison, and further tests are needed.

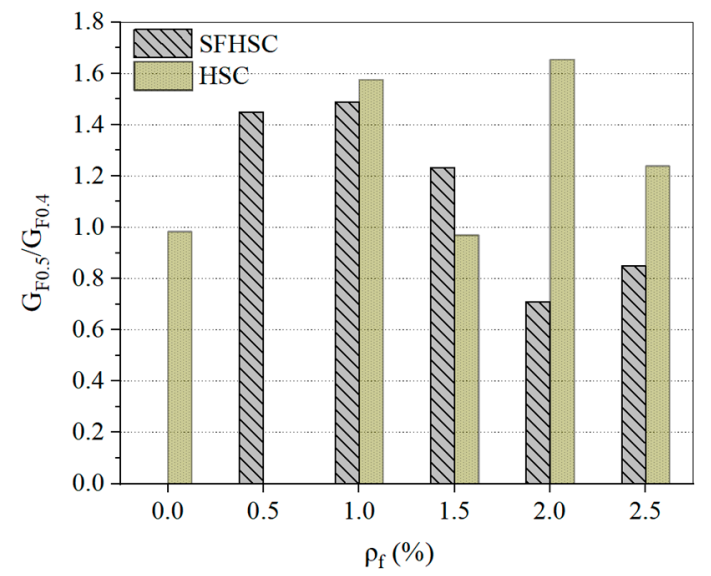

Figure 14. Influence of notch depth of beam on the fracture energy of SFHSC.

\subsection{Unified Calculation Model of SFHSC Behavior}

The $\mathrm{K}_{\mathrm{IC}}$ calculation model of SFHSC is defined as (6)

$$
K_{\mathrm{sIC}}=\left(1+\alpha_{s f, k} \lambda_{f}^{2}\right) K_{\mathrm{IC}}
$$

where $K_{\text {sIC }}$ is the fracture toughness of SFHSC, $K_{\mathrm{IC}}$ is the fracture toughness of the comparative group of concrete, $\lambda_{\mathrm{f}}$ is the characteristic parameter of steel fiber content, and $\alpha_{s f, k}$ is the increment coefficient of steel fiber to concrete fracture toughness considering the effect of steel fiber spacing.

According to the SFHSC fracture toughness test, the $K_{\text {IC }}$ increment coefficient of steel fiber to concrete, considering the fiber spacing effect, is $\alpha_{\mathrm{sf}, \mathrm{k}}=4.9382$. The average value of the ratio of the $K_{\mathrm{IC}}$ measured value to the calculated value according to Formula (6) is 1.0581 , the mean square error is 0.1125 , and the coefficient of variation is 0.1063 . Figure $15 \mathrm{a}$ shows the regression relationship between the measured $K_{\mathrm{sIC}}$ increment ratio and $\lambda_{\mathrm{f}}{ }^{2}$.

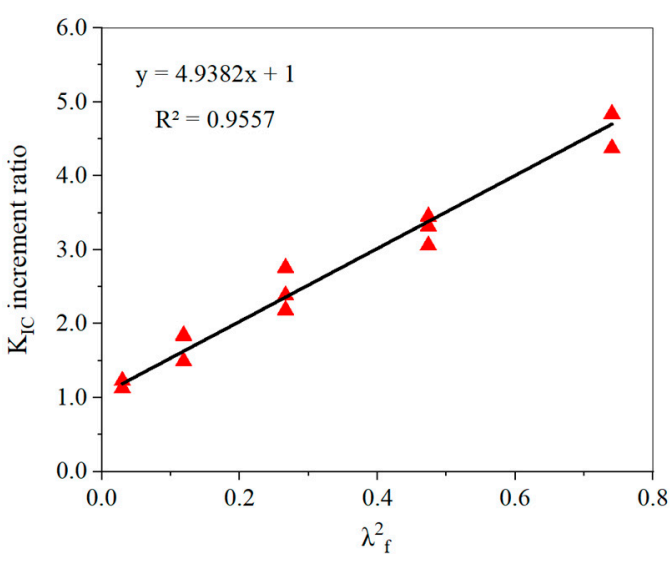

(a)

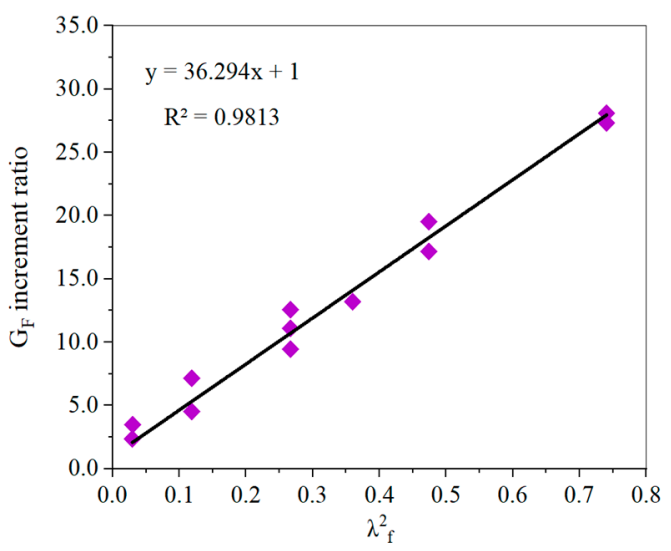

(b)

Figure 15. Regression curve of the $K_{I C}$ increment ratio v. s. $\lambda_{f}^{2}(\mathbf{a})$ and $G_{F}$ increment ratio v (b).

The calculation model of the $G_{F}$ of SFHSC is defined as (7):

$$
G_{s F}=\left(1+\alpha_{s f, g} \lambda_{f}^{2}\right) G_{F}
$$


where $G_{\mathrm{sF}}$ is the fracture energy of SFHSC, $G_{F}$ is the fracture energy of the comparative group of concrete, and $\alpha_{\text {sf,g }}$ is the increment coefficient of MF to concrete fracture energy considering the effect of steel fiber spacing.

According to the SFHSC fracture energy test, the increment coefficient of the fracture energy of steel fiber concrete considering the effect of fiber spacing is $\alpha_{\text {sf, g }}=36.296$. Excluding the significant variation data of MFT10-5, the average value of the ratio for the measured value of steel-fiber-reinforced concrete $G_{F}$ to the calculated value according to Formula (7) is 1.0031, the mean-square-error is 0.1054 , and the coefficient of variation is 0.1051 . Figure $15 \mathrm{~b}$ shows the regression curve of the experimental $G_{S F}$ increment ratio and $\lambda_{\mathrm{f}}{ }^{2}$.

\section{Conclusions}

Based on the TPBT of the notched concrete beam, the influence of the type of steel fiber, the volume fraction of steel fiber, and the relative notch depth on the fracture behavior of SHFSC was studied. In actual large-scale structural design projects, the fracture performance of the selected SHFSC can be measured and judged based on the conclusions and formulas offered in this study. The main conclusions are as follows:

(1) Steel fiber can significantly increase the $\mathrm{K}_{\mathrm{IC}}$ value of HSC. The $\rho_{f}$ increases by $0.5 \%$. When $\mathrm{a} / \mathrm{h}_{0}=0.4$ and $0.5, \mathrm{~K}_{\mathrm{IC}}$ increases by $40.7 \%$ and $45.7 \%$, respectively, and the average increment ratios are 2.75 and 2.87 , respectively.

(2) Steel fiber can more effectively improve the $G_{F}$ of HSC. The addition of steel fiber can significantly increase the HSC fracture energy, and leads to a steeper load-deflection curve ]. The peak load, peak deflection, and ultimate deflection all increase to varying degrees with an increase in $\rho_{f}$.

(3) The BF is most effective for improving the fracture behavior of SHFSC. The KIC values of the $\mathrm{BF}$ are 3.62 and 7.41 times those of the MF and SF, respectively. The $\mathrm{K}_{\mathrm{IC}}$ increment ratios of the $\mathrm{BF}$ are 3.17 and 7.77 times those of the MF and $\mathrm{SF}$, respectively. The $G_{F}$ values of the $B F$ are 6.57 and 5.85 times those of the MF and SF, respectively. The $\mathrm{G}_{\mathrm{F}}$ increment ratios of the $\mathrm{BF}$ are 7.06 and 5.67 times those of the MF and SF, respectively.

(4) A change in notch depth has no significant effect on the $\mathrm{K}_{\mathrm{IC}}$ of HSC specimens. The $\mathrm{K}_{\mathrm{IC}}$ of SFHSC specimens decreases slightly with an increase in the incision depth.

(5) Based on the statistical analysis of the test results, the calculation models for the fracture parameters of SFHSC with different strengths are obtained. The fracture toughness calculation model is expressed as $K_{\mathrm{sIC}}=\left(1+\alpha_{s f, k} \lambda_{f}^{2}\right) K_{\mathrm{IC}}$. The fracture energy calculation model is expressed as $G_{s F}=\left(1+\alpha_{s f, g} \lambda_{f}^{2}\right) G_{F}$.

In this paper, the fracture behavior of SHFSC is only studied through TPBTs, which can be further verified by comparative tests. The research on SHFSC materials is developing rapidly. Future work should explore the bridging role of fibers at a deeper level. The research will use concrete tests and construct a micro finite element model. Future work will also propose a model suitable for concrete design and application. Finally, a model suitable for concrete design and application will also be proposed.

Author Contributions: Conceptualization, S.Q. and Z.W.; methodology, Z.W.; software, S.Q.; validation, S.Q., Z.W., D.G. and H.Z.; formal analysis, S.Q.; resources, D.G.; data curation, Z.W.; writingoriginal draft preparation, S.Q.; writing-review and editing, S.Q.; supervision, Z.W.; funding acquisition, H.Z. All authors have read and agreed to the published version of the manuscript.

Funding: This research was funded by National Natural Science Foundation of China (51779231). This support is gratefully acknowledged.

Institutional Review Board Statement: Not applicable.

Informed Consent Statement: Not applicable.

Data Availability Statement: Data sharing not applicable. 
Conflicts of Interest: The authors declare no conflict of interest.

\section{References}

1. Bernal, J.; Reyes, E.; Massana, J.; León, N.; Sánchez, E. Fresh and mechanical behavior of a self-compacting concrete with additions of nano-silica, silica fume and ternary mixtures. Constr. Build. Mater. 2018, 160, 196-210. [CrossRef]

2. Shen, D.; Liu, X.; Li, Q.; Sun, L.; Wang, W. Early-age behavior and cracking resistance of high-strength concrete reinforced with Dramix 3D steel fiber. Constr. Build. Mater. 2018, 196, 307-316. [CrossRef]

3. Jin, L.; Zhang, R.; Tian, Y.; Dou, G.; Du, X. Experimental investigation on static and dynamic mechanical properties of steel fiber reinforced ultra-high-strength concretes. Constr. Build. Mater. 2018, 178, 102-111. [CrossRef]

4. Sun, X.; Gao, Z.; Cao, P.; Zhou, G.; Ling, Y.; Wang, X.; Zhao, Y.; Diao, M. Fracture performance and numerical simulation of basalt fiber concrete using three-point bending test on notched beam. Constr. Build. Mater. 2019, 225, 788-800. [CrossRef]

5. Mousavi, S.M.; Ranjbar, M.M.; Madandoust, R. Combined effects of steel fibers and water to cementitious materials ratio on the fracture behavior and brittleness of high strength concrete. Eng. Fract. Mech. 2019, 216, 106517. [CrossRef]

6. Aziminezhad, M.; Mardi, S.; Hajikarimi, P.; Nejad, F.M.; Gandomi, A.H. Loading rate effect on fracture behavior of fiber reinforced high strength concrete using a semi-circular bending test. Constr. Build. Mater. 2020, 240, 117681. [CrossRef]

7. Xu, B.W.; Shi, H.S. Correlations among mechanical properties of steel fiber reinforced concrete. Constr. Build. Mater. 2009, 23, 3468-3474. [CrossRef]

8. Kizilkanat, A.B.; Kabay, N.; Akyüncü, V.; Chowdhury, S.; Akça, A.H. Mechanical properties and fracture behavior of basalt and glass fiber reinforced concrete: An experimental study. Constr. Build. Mater. 2015, 100, 218-224. [CrossRef]

9. Afroughsabet, V.; Ozbakkaloglu, T. Mechanical and durability properties of high-strength concrete containing steel and polypropylene fibers. Constr. Build. Mater. 2015, 94, 73-82. [CrossRef]

10. Hwang, P.S.S. Mechanical properties of high-strength steel fiber-reinforced concrete. Constr. Build. Mater. 2004, 9, 669-673.

11. Taha, M.M.R.; Shrive, N.G. Enhancing Fracture Toughness of High-Performance Carbon Fiber Cement Composites. ACI Mater. J. 2001, 98, 168-178.

12. Hao, Y.; Hao, H. Dynamic compressive behavior of spiral steel fiber reinforced concrete in split Hopkinson pressure bar tests. Constr. Build. Mater. 2013, 48, 521-532. [CrossRef]

13. RILEM. Determination of the Fracture Energy of Mortar and Concrete by Means of Three-Point Bend Tests on Notched Beams, Draft Recommendation (50-FMC). Mater. Struct. 1985, 18, 484. [CrossRef]

14. Tschegg, E.K.; Schneemayer, A.; Merta, I.; Rieder, K.A. Energy dissipation capacity of fibre reinforce concrete under biaxial tension-compression load. Part II: Determination of the fracture process zone with the acoustic emission technique. Cem. Concr. Compos. 2015, 62, 187-194. [CrossRef]

15. Şahin, Y.; Köksal, F. The influences of matrix and steel fibre tensile strengths on the fracture energy of high-strength concrete. Constr. Build. Mater. 2011, 25, 1801-1806. [CrossRef]

16. Kazemi, M.T.; Fazileh, F.; Ebrahiminezhad, M.A. Cohesive Crack Model and Fracture Energy of Steel-Fiber-Reinforced-Concrete Notched Cylindrical Specimens. J. Mater. Civ. Eng. 2007, 19, 884-890. [CrossRef]

17. Chalioris, C.E. Analytical approach for the evaluation of minimum fiber factor required for steel fibrous concrete beams under combined shear and flexure. Constr. Build. Mater. 2013, 43, 317-336. [CrossRef]

18. Chalioris, C.E.; Karayannis, C.G. Effectiveness of the use of steel fibers on the torsional behavior of flanged concrete beams. Cem. Concr. Compos. 2009, 31, 331-341. [CrossRef]

19. Usman, M.; Farooq, H.S.; Omair, M.; Hanif, A. Axial compressive behavior of confined steel fiber reinforced high strength concrete. Constr. Build. Mater. 2020, 230, 117043. [CrossRef]

20. Yoo, D.Y.; Yoon, Y.S.; Banthia, N. Predicting the post-cracking behavior of normal- and high-strength steel-fiber-reinforced concrete beams. Constr. Build. Mater. 2015, 93, 477-485. [CrossRef]

21. Şemsi, Y. Effect of aspect ratio and volume fraction of steel fiber on the mechanical properties of SFRC. Constr. Build. Mater. 2007, $21,1250-1253$.

22. Zhang, P.; Guan, Y.Q.; Liu, H.C.; Li, F.Q. Study on Notch Sensitivity of Fracture Properties of Concrete Containing Nano-SiO 2 Particles and Fly Ash. J. Nanomater. 2013, 2013, 1-7.

23. Carpinteri, A.; Ingraffea, A.R.; Bazant, Z.P. Fracture Mechanics of Concrete: Material Characterization and Testing. J. Appl. Mech. 1984, 53, 477. [CrossRef]

24. Hillerborg, A.; Modéer, M.; Petersson, P.E. Analysis of crack formation and crack growth in concrete by means of fracture mechanics and finite elements. Cem. Concr. Res. 1976, 6, 773-781. [CrossRef]

25. Hillerborg, A. The theoretical basis of a method to determine the fracture energy GF of concrete. Mater. Struct. 1985, 18, 291-296. [CrossRef]

26. Hu, Y.; Wang, J.; Zhang, C.; Li, H.; Hu, X. Notch sensitivity of reinforced concrete in fracture tests. Eng. Fract. Mech. 1993, 46, 677-681. [CrossRef]

27. Kovler, Y.V.Z.L. Notch sensitivity of concrete and size effect Part I: Effect of specimen size and crack length by 3-point bending. Cem. Concr. Res. 1985, 6, 979-987.

28. Ren, X.; Li, J. Multi-scale based fracture and damage analysis of steel fiber reinforced concrete. Eng. Fail. Anal. 2013, 35, $253-261$. [CrossRef] 
29. Elik, Z.; Bingl, A.F. Fracture properties and impact resistance of self-compacting fiber reinforced concrete (SCFRC). Mater. Struct. 2020, 53, 1-16

30. Jorbat, M.H.; Hosseini, M.; Mahdikhani, M. Effect of polypropylene fibers on the mode I, mode II, and mixed-mode fracture toughness and crack propagation in fiber-reinforced concrete. Theor. Appl. Fract. Mech. 2020, 109, 102723. [CrossRef]

31. Deng, Z. The fracture and fatigue performance in flexure of carbon fiber reinforced concrete. Cem. Concr. Compos. 2005, 27, 131-140. [CrossRef]

32. Wu, Z.; Shi, C.; He, W.; Wu, L. Effects of steel fiber content and shape on mechanical properties of ultra high performance concrete Constr. Build. Mater. 2016, 103, 8-14. [CrossRef]

33. Güneyisi, E.; Gesoglu, M.; Özturan, T.; Ipek, S. Fracture behavior and mechanical properties of concrete with artificial lightweight aggregate and steel fiber. Constr. Build. Mater. 2015, 84, 156-168. [CrossRef]

34. Choi, W.-C.; Jung, K.-Y.; Jang, S.-J.; Yun, H.-D. The Influence of Steel Fiber Tensile Strengths and Aspect Ratios on the Fracture Properties of High-Strength Concrete. Materials 2019, 12, 2105. [CrossRef] [PubMed]

35. Christidis, K.I.; Badogiannis, E.G.; Mintzoli, C. Flexural behavior of pumice lightweight concrete reinforced with end-hooked steel fibres. Structures 2021, 33, 3835-3847. [CrossRef]

36. Parthiban, P.; Kar, S.; Mondal, A.K.; Gunasekar, S.; Shaisundaram, V. Stress-strain behaviour of (hpfrc) high-performance fibre reinforced concrete: An experimental study. Mater. Today Proc. 2021. [CrossRef]

37. Kazemi, M.; Golsorkhtabar, H.; Beygi, M.; Gholamitabar, M. Fracture properties of steel fiber reinforced high strength concrete using work of fracture and size effect methods. Constr. Build. Mater. 2017, 142, 482-489. [CrossRef]

38. Zhang, X.X.; Elazim, A.; Ruiz, G.; Yu, R.C. Fracture behaviour of steel fiber-reinforced concrete at a wide range of loading rates Int. J. Impact Eng. 2014, 71, 89-96. [CrossRef]

39. Standard of China Engineering Construction Standardization Association of the People's Republic of China. Test Method for Steel Fiber Reinforced Concrete, CECS13:89; China Planning Press: Beijing, China, 1989.

40. Standard of China Engineering Construction Standardization Association of the People's Republic of China. Standard Test Methods for Fiber Reinforced Conrete, CECS13:09; China Planning Press: Beijing, China, 2009.

41. Kizilkanat, A.B. Experimental Evaluation of Mechanical Properties and Fracture Behavior of Carbon Fiber Reinforced High Strength Concrete. Period. Polytech. Civ. Eng. 2016, 6, 289-296. [CrossRef]

42. Qian, C.X.; Stroeven, P. Development of hybrid polypropylene-steel fiber-reinforced concrete. Cem. Concr. Res. 2000, 30, 63-69. [CrossRef]

43. Wang, X.W.; Tian, W.L.; Fan, L.L.; Zhou, M.J.; Zhao, X.Y. Research on Fracture-CMOD Toughness of Steel Fiber Reinforced Concrete. Adv. Mater. Res. 2010, 168-170, 1784-1787. [CrossRef] 